\title{
Agoraphobia and Panic
}

\section{Prospective-Longitudinal Relations Suggest a Rethinking of Diagnostic Concepts}

\author{
Hans-Ulrich Wittchen ${ }^{a, b}$ Agnes Nocon $^{b}$ Katja Beesdo ${ }^{a}$ Daniel S. Pine ${ }^{c}$ \\ Michael Höfler ${ }^{a}$ Roselind Lieb ${ }^{b, d}$ Andrew T. Gloster ${ }^{a}$ \\ a Institute of Clinical Psychology and Psychotherapy, Technische Universität Dresden, Dresden, and \\ ${ }^{b}$ Max Planck Institute of Psychiatry, Research Group of Molecular Psychology, Munich, Germany; ${ }^{C}$ Mood and Anxiety \\ Disorders Program, National Institute of Mental Health, Division of Intramural Research Programs, Bethesda Md., USA; \\ ${ }^{d}$ Institute of Psychology, Epidemiology and Health Psychology, University of Basel, Basel, Switzerland
}

\section{Key Words}

Panic disorder · Agoraphobia · Longitudinal · Anxiety · DSM

\begin{abstract}
Background: The relationship of panic attacks (PA), panic disorder (PD) and agoraphobia (AG) is controversial. The aim of the current study is to prospectively examine the 10-year natural course of PA, PD and AG in the first three decades of life, their stability and their reciprocal transitions. Methods: DSM-IV syndromes were assessed via Composite International Diagnostic Interview - Munich version in a 10-year prospective-longitudinal community study of 3,021 subjects aged 14-24 years at baseline. Results: (1) Incidence patterns for PA (9.4\%), PD (with and without AG: 3.4\%) and AG (5.3\%) revealed differences in age of onset, incidence risk and gender differentiation. (2) Temporally primary PA and PD revealed only a moderately increased risk for subsequent onset of $A G$, and primary $A G$ had an even lower risk for subsequent PA and PD. (3) In strictly prospective analyses, all baseline groups (PA, PD, AG) had low remission rates (0-23\%). Baseline $P D$ with $A G$ or $A G$ with PA were more likely to have follow-up $A G, P A$ and other anxiety disorders and more frequent complications (impairment, disability, help-seeking, comorbidi-
\end{abstract}

The first 2 authors should be regarded as joint first authors. ty) as compared to PD without AG and AG without PA. Conclusions: Differences in incidence patterns, syndrome progression and outcome, and syndrome stability over time indicate that AG exists as a clinically significant phobic condition independent of PD. The majority of agoraphobic subjects in this community sample never experienced PA, calling into question the current pathogenic assumptions underlying the classification of AG as merely a consequence of panic. The findings point to the necessity of rethinking diagnostic concepts and DSM diagnostic hierarchies.

Copyright $\odot 2008$ S. Karger AG, Basel

\section{Background}

The question of whether agoraphobia (AG) constitutes a separate, independent diagnostic category distinct from panic attacks (PA) and panic disorder (PD) is a matter of contention [1-10]. DSM-IV hierarchy rules result in the nearly unconditional priority of PA and PD over the diagnosis of AG. That is, AG is not a codable disorder but is rather diagnosed only in the context of PD (i.e., PD with AG) or as the result of PA or panic-like features (i.e., AG without a history of PD). The subordinate status of AG is inconsistent with epidemiological studies, which have repeatedly observed a substantial portion of AG cases that occur independently of PA [4, 11-21] with similar degrees of associated impairments [22, 23].

\section{KARGER}

(C) 2008 S. Karger AG, Basel

Fax +41613061234

E-Mail karger@karger.ch

www.karger.com
Accessible online at: www.karger.com/pps
Hans-Ulrich Wittchen

Institute of Clinical Psychology and Psychotherapy, Technische Universität Dresden

Chemnitzer Strasse 46, DE-01187 Dresden (Germany)

Tel. +49351 463 38577, Fax +4935146336984

E-Mail wittchen@psychologie.tu-dresden.de 
The residual status of AG in the DSM-IV emphasizes one etiological pathway to the exclusion of others. The DSM perspective links spontaneous PA and its assumed neurobiological and neuropsychological role to subsequent AG. In contrast, independent conceptualizations of AG do not view PA as a necessary etiological precursor, though it is one possible pathway to AG in clinical populations [9, 24-30]. These distinctions have clear implications for nosological issues and can also affect treatment. For instance, current hierarchical rules might result in underrecognition and undertreatment of AG. Further, the DSM perspective suggests targeting primarily panicrelated symptoms and the associated catastrophic cognitions. In contrast, AG patients who have never had paniclike symptoms may more closely resemble subjects with specific phobia and therapy may require predominantly targeting agoraphobic avoidance by situational exposure [31-33].

In order to investigate the independence of $A G$ and $\mathrm{PA} / \mathrm{PD}$, we collected prospective longitudinal data during high-risk periods for psychopathological development (i.e., adolescence and young adulthood). Furthermore, we measured these constructs using assessment algorithms that allowed for nonhierarchical responses, lest they could only substantiate the diagnoses from which the definitions were derived. In our previous study $[4,34]$, we found evidence for the existence of a fairly large, clinically impaired group of AG that occurred not only outside the context of PD but without any notable signs of PA or panic-like symptoms. That study was noteworthy because all AG cases were verified by independent clinical reviewers based on strict definitions. The results suggested that various etiological pathways lead to AG, some with and some without panic symptoms. As a follow-up, the current study continues this exploration by examining the 10 -year natural course, incidence and prospective temporal patterns of symptoms and associated impairments of PA, PD and AG with and without the use of hierarchical rules. Thus, the current study tests the longitudinal stability and validity of our previous findings. Overall, the goal of the current study was to further examine the diagnostic independence of $A G$ and the role of PA and PD in its etiology. To this end, we (1) describe patterns of incidence of PA, AG and PD; (2) investigate the natural course and reciprocal transitions of these syndromes with each other, and (3) examine the degree to which the syndromes differ on selected clinical correlates.

\section{Methods}

\section{Subjects and Setting}

Data were collected under the auspices of the Early Developmental Stages of Psychopathology Study, a prospective cohort study of the prevalence, incidence, familial and other risk factors, comorbidity and course of mental disorders in a representative sample of adolescents and young adults in Munich, Germany. The study consisted of a baseline survey, three follow-up surveys and two family supplements (not dealt with in this paper). The baseline sample was drawn randomly from the 1994 government registry of all residents aged 14-24 years in greater metropolitan $\mathrm{Mu}-$ nich. Consistent with the aim of studying the onset of mental disorders, respondents aged 14-15 years were sampled at four times the probability of 22- to 24-year-olds, and respondents aged 16-21 years were sampled at twice the probability of 22- to 24year-olds [35-37].

The results reported in this article are based on 3,021 respondents, except for prospective analyses in the subset of independently validated cases with baseline diagnoses of PA, PD and AG.

\section{Diagnostic Assessment}

The standardized diagnostic assessment interview Composite International Diagnostic Interview - Munich version (DIA-X/ M-CIDI) [38] was used to evaluate symptoms, syndromes and diagnoses according to DSM-IV and ICD-10 criteria. Psychometric properties of the Composite International Diagnostic Interview have been established in several studies, with excellent results for PA, PD and AG [39-41].

\section{Measures of Panic and Agoraphobia}

Assessment of PD began with the question: 'Have you ever had an attack when all of a sudden you felt frightened, anxious or very uneasy?' When endorsed, the respondents were asked whether at least one attack occurred 'out of the blue' and to provide examples that were recorded verbatim. Twenty-one questions about the DSM-IV criteria for PA and PD followed. In addition, the patients were queried about their help-seeking behaviors, results of medical evaluations, as well as the age of onset, frequency and context of the attacks (i.e. situationally predisposed or situationally bound agoraphobic and social situations). No skips were used in the assessment of PA, thus allowing for the evaluation of various subthreshold manifestations, such as fearful spells (FS).

All participants were assessed for AG, irrespective of their answers to the panic sections. The AG stem question assed six mandatory situations: 'Have you ever had a strong fear of or did you avoid (a) leaving your home or being outside your home, (b) traveling in a bus, train or car, (c) being in a crowd or standing in a line, (d) being in a public place, like a shop, (e) going on a long journey, (f) crossing a bridge?' If at least one situation was endorsed, the respondents were asked to give examples of what was feared in these situations. As in the panic section, answers were recorded verbatim. Subsequently, DSM-IV criteria were probed (e.g., frequency/degree of avoidance, distress or impairment, etc.). It is important to note that, so assessed, the focus of AG is on the feared situations themselves and not, as stated in the DSM-IV definition of AG without history of PD, 'on the occurrence of incapacitating or extremely embarrassing panic-like symptoms or limited-symptom attacks' [42, p. 403]. Verbatim responses along 
with treatment information were clinically validated via case reviews by three independent US clinical psychologists and psychiatrists highly experienced in anxiety and clinical interviews. This processes yielded unanimous agreement on all cases of AG with at least two trigger situations as 'true' cases of AG [4]. Definitions of panic and AG are consistent with those used in our previous analyses, including the convention of diagnosing AG only when two or more agoraphobic trigger situations were present.

\section{Diagnostic Comparison Groups}

The results in the present paper are based on two different groups of participants. First, the total sample $(n=3,021)$ was used to investigate cumulative incidence patterns and associations. We examined PA, PD and AG with and without the use of DSM-IV hierarchical rules. As shown in figure 1 (bold), use of hierarchy rules examined across all assessment waves resulted in 54 PD with AG, 47 PD without AG (PD total: $\mathrm{n}=101$ ) and 21 AG without the history of PD. Without hierarchy rules, 283 met criteria for DSMIV PA, 154 for AG and 101 for PD. It should be noted that among the 154 cases with AG, 45 revealed no history of either PA or any panic-like experiences.

Second, only independently verified baseline cases [4] were used for prospective analyses. This strategy provided a stricter test of transitions in terms of conditional probabilities and eliminated the possibility of misdiagnosis. This subset (total baseline $\mathrm{n}=180$ ) consists of 20 cases with PD with AG, 22 PD without AG and 69 cases of AG without a history of PD when using diagnostic hierarchies; 69 had PA only at baseline. Without DSM-IV hierarchical rules 122 PA cases, 42 PD cases and 89 AG cases were identified. Due to follow-up attrition, the number of eligible cases for the strict prospective analysis was slightly reduced, leaving 108 PA, $38 \mathrm{PD}$ and 80 AG cases.

\section{Clinical Characteristics and Comorbid Disorders}

Age of onset was defined as the lowest age of onset reported at baseline or at follow-up. Social role impairment was based on impairment in various social roles caused by the fear of situations or agoraphobic avoidance in the four weeks prior to the interview. Disability was defined as the mean number of disability days due to mental problems across all available interviews. Finally, helpseeking was defined as having contacted a medical doctor or another health professional about problems due to panic or agoraphobic symptoms.

\section{Data Analysis}

Baseline prevalence covers the respondents' life up to the baseline assessment. The complete follow-up status is based on the aggregated information through follow-up. Cumulative incidence was calculated by aggregating baseline, first, second and third follow-up information. In the case of nonresponses, last observation carried forward methodology was used. Data are weighted by sex, age and geographic location at baseline to match the distribution of the sampling frame [36]. The 'robust sandwich method' was used for statistical inference with weighted data [43]. Differences in binary outcomes were assessed with odds ratios (ORs) from logistic regressions. The number of available observations varied slightly between analyses due to missing information. For all analyses the statistical significance was set at the $5 \%$ level $(\mathrm{p}<0.05$, 2-tailed).

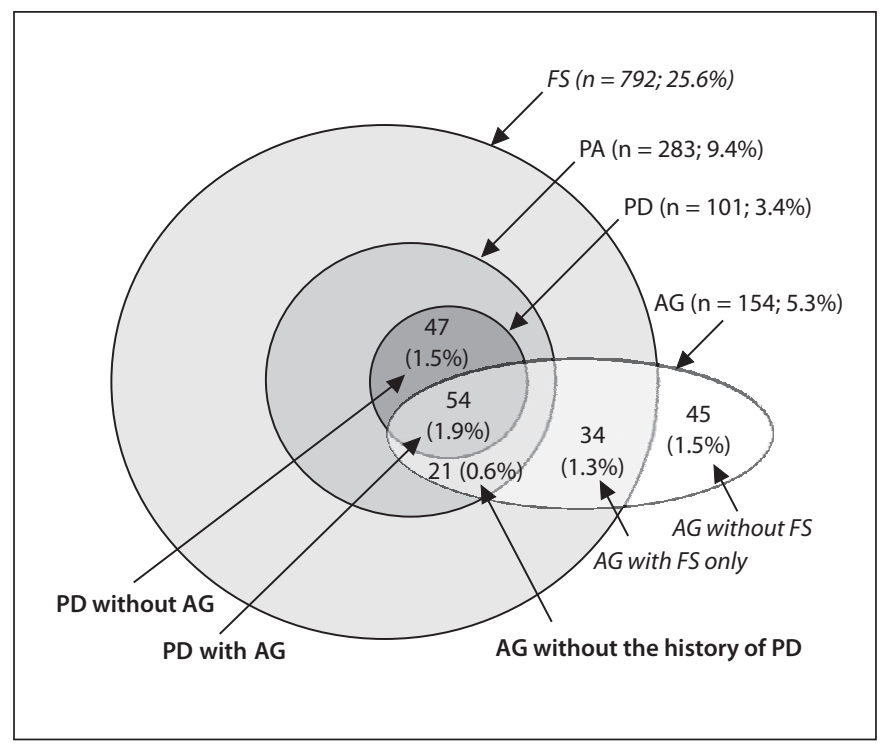

Fig. 1. Cumulative lifetime incidence (up to the age of 34) of fearful spell (FS), DSM-IV PA, DSM-IV PD and DSM-IV AG ( $\mathrm{n}=$ 3,021). Bold labels represent DSM-IV diagnoses; italic labels are terms which do not appear in the DSM-IV; hierarchical diagnostic groups are in the lower half of the figure and nonhierarchical ones in the upper half.

Curves were fit according to gender and baseline age ('stratified Cox regression'). To account for large confidence intervals (CI) with limited interpretability, all survival curves are presented only if at least 20 subjects were under risk. Otherwise the curve was cut at the respective age. Additionally, we assessed differences with regard to age cohort (14-17 years vs. 18-24 years at baseline), gender and the interaction of both on the longitudinal incidence using hazard ratios (HRs) from Cox regression. We fit the Cox regressions stratified for sex and age cohort if both variables were not of primary interest. The model fit was assessed with Schönfeld residuals [44]. A violation of the assumptions would indicate that the respective effect was not constant over the entire age period. The main effect of cohort as well as the interactions for cohort and gender on the longitudinal incidence can only be estimated in the life period that all respondents had passed equally, that is up to the age of 21 (as the youngest participants were 21 years at the final assessment). We also assessed whether the mean age of onset differed by gender if the respondent developed the outcome. Therefore we added the interaction term gender $x$ time to the model. The age-dependent HR in such a model is given by the term HR (main effect) $\times$ HR (interaction) ${ }^{\text {age }}$. Finally, we assessed whether the risk for PA, PD or AG (outcome) was higher in cases where another syndrome (condition) X preceded the onset of the outcome using age of onset information on X. Therefore we computed the main effect of the age-dependent variable $\mathrm{X}(\mathrm{t})$ 'condition before outcome', where $\mathrm{X}(\mathrm{t})$ equals 1 if $\mathrm{X}$ occurs before age $\mathrm{t}-1$ and equals 0 otherwise. Therefore we computed the main effect of the age-dependent variable 'condition before outcome'. This implies that the condition predates the outcome by at least one year. 


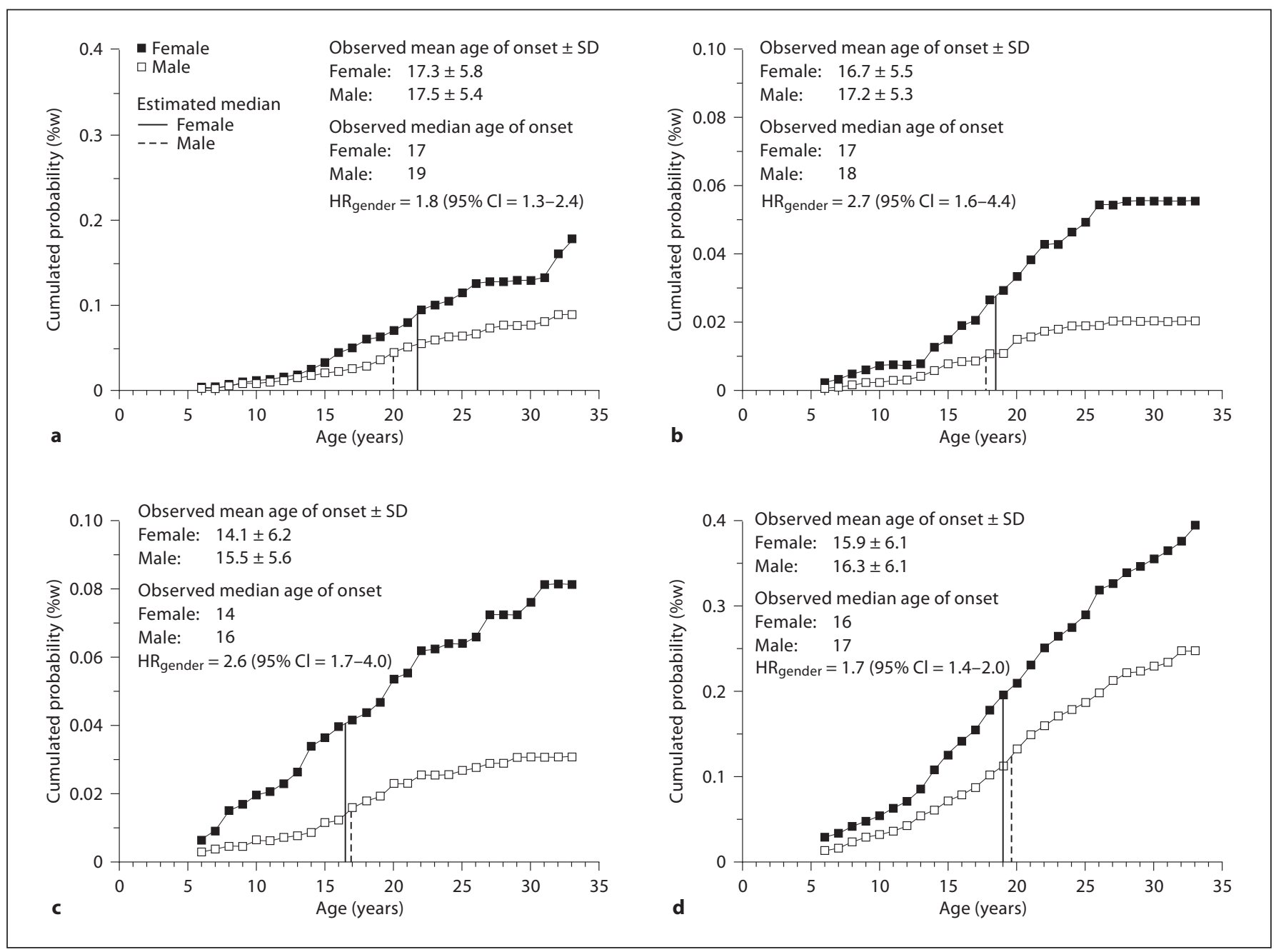

Fig. 2. Cumulative incidence by gender of PA (a), PD (b), AG (c) and FS (d) with and without panic symptoms up to the third follow-up $(\mathrm{n}=3,021)$. Estimated median was calculated by dividing the cumulated probability at age 34 years by two and identifying the corresponding age at which that incidence was achieved.

\section{Results}

\section{Incidence Patterns of Panic and Agoraphobia}

Figure 1 presents the number of individuals and the $\mathrm{cu}$ mulated incidences of PA (9.4\%), PD (3.4\%) and AG (5.3\%) and their overlap in the total sample. Using strict DSM-IV diagnostic criteria, the rates for PD without AG were 1.5\%, $1.9 \%$ for $\mathrm{PD}$ with $\mathrm{AG}$ and $0.6 \%$ for AG without the history of PD. The difference between hierarchical (bold) and nonhierarchical definitions resulted in a majority [(34+ $45) / 154=51.3 \%$ ] of agoraphobic cases who would go formally undiagnosed within the panic-AG spectrum. These individuals without a diagnosis result because they did not experience PA as required in DSM-IV-TR (i.e., AG with FS only $=1.3 \%$ and $\mathrm{AG}$ without $\mathrm{FS}=1.5 \%$ ). It is especially salient that more than half of those did not even experience extremely broadly defined panic-like symptoms (i.e., AG without FS; $45 / 79=57.0 \%$ ) and represent nearly a third of all agoraphobic subjects $(45 / 154=29.2 \%)$.

As evidenced by figure 2, PA, PD and AG develop in considerably diverse ways. Onset of PA before the age of 13 was rare (estimated median: females $=21.5$ years, males $=20$ years), and gender differences were not apparent before the age of 15. Further, the data suggest a leveling off of incidence for women at the age of $26^{1}$. Similar to PA,

\footnotetext{
1 The indication for a second peak appearing after the age of 30 should be regarded with caution because of the low number of observations.
} 
Table 1. Temporally directed association between PA, PD and AG (total data set, $\mathrm{n}=3,021$, without diagnostic hierarchies)

\begin{tabular}{|c|c|c|c|c|c|c|c|c|c|c|}
\hline \multirow{2}{*}{$\begin{array}{l}\text { Temporal pattern } \\
\text { (primary to } \\
\text { subsequent condition) }\end{array}$} & \multirow[t]{2}{*}{ Total } & \multirow{2}{*}{$\begin{array}{l}\text { Eligible } \\
\text { number at } \\
\text { risk }\end{array}$} & \multicolumn{2}{|c|}{$\begin{array}{l}\text { Observed num- } \\
\text { ber of outcomes }\end{array}$} & \multicolumn{2}{|c|}{$\begin{array}{l}\text { Overall } \\
\text { associations }\end{array}$} & \multicolumn{4}{|c|}{ Model including interaction with age } \\
\hline & & & $\mathrm{n}$ & $\% w$ & HR & $95 \%$ CI & $\begin{array}{l}\text { HR (main } \\
\text { effect) }\end{array}$ & $95 \%$ CI & $\begin{array}{l}\text { HR (inter- } \\
\text { action effect) }{ }^{1}\end{array}$ & $95 \%$ CI \\
\hline PA to PD & 283 & 277 & 100 & 37.0 & - & - & - & - & - & - \\
\hline No PA to PD & 2,738 & 2,738 & 0 & 0.0 & & & & & & \\
\hline PA to AG & 283 & 264 & 60 & 23.5 & 26.7 & $17.2-41.7$ & 124.5 & $40.9-378.7$ & 0.9 & $0.85-0.97$ \\
\hline No PA to AG & 2,738 & 2,732 & 87 & 3.1 & & & & & & \\
\hline $\mathrm{PD}$ to $\mathrm{AG}$ & 101 & 98 & 51 & 54.9 & 62.5 & $38.5-101.2$ & 228.6 & $62.7-833.0$ & 0.9 & $0.86-1.1$ \\
\hline No PD to AG & 2,920 & 2,914 & 96 & 3.3 & & & & & & \\
\hline AG to $P A$ & 154 & 135 & 13 & 11.6 & 1.8 & $0.9-3.5$ & & & & \\
\hline No AG to PA & 2,867 & 2,863 & 264 & 8.8 & & & & & & \\
\hline$A G$ to $P D$ & 154 & 92 & 2 & 2.4 & 1.0 & $0.2-4.9$ & & & & \\
\hline No AG to PD & 2,867 & 2,867 & 98 & 3.3 & & & & & & \\
\hline
\end{tabular}

Eligible number at risk: number at risk - number of eligible subjects at risk for temporally secondary disorder during follow-up. Numbers differ because of varying numbers of subjects who either developed the outcome preceding the condition or had no age of onset information. $\% \mathrm{w}=$ Weighted percent; $\mathrm{HR}=$ hazard ratio, reference group is the group without preceding syndrome.

${ }^{1}$ Age-dependent HR $=$ HR $($ main effect $) \times$ HR (interaction effect) ${ }^{\text {age }}$.

the incidence for PD reveals a very clear-cut period of increased incidence in women between the ages of 13 and 26, with no new onsets of PD after this age. Males displayed considerably lower estimates and the period of increased incidence is less pronounced. However, similar to women there were no new onsets after the age of 25 . It should be noted that unlike PA, the gender difference is apparent in cases before the age of 14 but widens considerably further between the ages of 14 and 25. In contrast to $\mathrm{PA}$ and PD, AG unanimously reveals a strong and steady incidence increase for females after the age of 6 (estimated median: 19). AG in males was observed considerably less frequently, with some indication of increased incidence between the ages of 15 and 20 and a leveling off after the age of 25 (estimated median: 17.5). The onset of FS can occur at any point after the age of 5 in both sexes (estimated median: females $=19$, males $=19.5$ ), with increasing gender differences emerging after the age of 12 .

All syndromes showed a higher risk for women with no indication that women had a significantly earlier onset than men. The gender-specific hazards ranged from 1.7 (FS) to 2.7 (PD). Further, no significant risk difference emerged between the younger and older birth cohort (14to 17 -year-olds vs. 18 - to 24 -year-olds at baseline) or between different combinations of gender and age cohort for any condition.

PDAG in the First Three Decades

\section{Transitions: Risk of PA, PD and AG by Preceding} Diagnostic Status

In this section we examined the implicit DSM-IV assumption that AG results from primary PA. Specifically, we investigated how frequently temporally primary $\mathrm{PA}$ or PD were associated with subsequent AG. Further, we examined how frequently temporally primary AG with and without PA were associated with subsequent PA or PD. For these analyses, the full data set and age of onset information for each condition was used for temporal ordering. Reference groups for these analyses consisted of the individuals who developed the outcome disorder but did not previously have the reference disorder (see table 1).

Consistent with the definition of PD, PA preceded PD in all observed outcomes. Nearly a quarter (23.5\%) of the subjects who had a PA developed subsequent AG and slightly more than half of the cases with PD developed subsequent AG (54.9\%). Likewise, the overall hazard ratios for these two temporal patterns were highly pronounced with CI suggesting at least a 17 -fold risk to develop AG after onset of PA and at least a 38 -fold risk to develop AG after onset of PD as compared to subjects without PA. Moreover, as indicted by the interaction terms with age, the hazard ratio of PA decreases significantly with increasing age, indicating that the prior con-

Psychother Psychosom 2008;77:147-157 
dition is also related to an accelerated onset of the outcome. This might possibly be due to a significant interaction with age, suggesting that the lower the age of onset of PA, the greater the risk of developing subsequent AG - at least when compared to individuals who developed AG without previous PA. Taken together, these findings suggest that the occurrence of $\mathrm{PA}$ and $\mathrm{PD}$ significantly increases the odds of developing AG. It should be noted, however, that odds determined from the hazard ratios are calculated in reference to the individuals who never had PA or PD and developed AG. Furthermore, $45.1 \%$ of the individuals at risk with PD and $76.5 \%$ of those at risk with PA did not develop AG. Subjects with AG did not have significantly increased odds of developing a subsequent PA or PD. This is also evidenced by the fact that only $11.6 \%$ of those with AG developed a subsequent PA and only $2.4 \%$ developed a subsequent PD.

\section{Strict Prospective Analysis of Diagnostic Stability and}

\section{Transitions}

The previous analyses using the total data set $(\mathrm{n}=$ 3,021) were repeated with the subset of independently validated cases in a strictly prospective-longitudinal manner. Although this is associated with some loss of statistical power due to attrition and lower base rates, it provides a more stringent examination of diagnostic stability and transitions by limiting the effects of recall bias. Additionally, this approach has the advantage of examining not only the question of transition but also the issues of remission and stability. These analyses used hierarchically defined, verified baseline cases of PA, PD and AG to prospectively examine the further course over the followup period. The follow-up occurrence of $\mathrm{PA}, \mathrm{PD}, \mathrm{AG}$ and other anxiety disorders in the follow-up period was determined without the use of diagnostic hierarchies. For each comparison ORs were estimated with a reference group of subjects with neither diagnostic condition. Baseline cases were classified as remitted when neither PA nor any other DSM-IV disorder was observed in the followup period.

As shown in table 2, baseline PA and PD cases did not have a significantly increased risk for subsequent AG (PA: 3.3\%, OR: 1.4 , 95\% CI: 0.3-7.2; PD: 10.0\%, OR: 4.1, 95\% CI: 0.9-19.5) as compared to the reference group with neither PA nor AG. In contrast, all diagnostic groups with baseline AG (i.e., AG without PA, AG with PA and PD with $A G$ ) had elevated risks for subsequent $A G$ during the follow-up period. Examination of the follow-up status of $\mathrm{PA} / \mathrm{PD}$ revealed a different pattern. All baseline diagnostic groups except for AG without PA clearly increased the odds of subsequent PA/PD. The increased odds for subsequent $\mathrm{PA} / \mathrm{PD}$ given baseline $\mathrm{AG}$ without $\mathrm{PA}$ were not statistically significant and much weaker than other baseline groups. It should be further noted that all baseline diagnostic groups except for PD without AG had decreased odds of follow-up remission (i.e., no disorder), suggesting that these baseline conditions are risk factors for subsequent psychopathology.

\section{Selected Clinical Correlates of Panic and Agoraphobia}

We also examined whether PD with and without AG and AG without the history of PD differed from the AG

Table 2. Risk (percent, OR) of baseline diagnostic groups (mutually exclusive) for being diagnosed as having AG, PA/PD, other anxiety disorders or any diagnosis during the follow-up period (not mutually exclusive)

\begin{tabular}{|c|c|c|c|c|c|c|c|c|c|c|c|c|}
\hline \multirow{3}{*}{$\begin{array}{l}\text { Baseline status } \\
\text { (mutually exclusive } \\
\text { diagnostic groups) }\end{array}$} & \multirow{2}{*}{\multicolumn{4}{|c|}{ Baseline prevalence }} & \multicolumn{8}{|c|}{ Follow-up status (at first, second or third follow-up assessment) } \\
\hline & & & & & \multicolumn{4}{|l|}{ AG } & \multicolumn{4}{|c|}{$\mathrm{PA} / \mathrm{PD}$} \\
\hline & $\mathrm{n}$ & $\% \mathrm{w}$ & $\mathrm{Ne}$ & $\% \mathrm{w}$ & $\begin{array}{l}\% w \\
\text { no }\end{array}$ & $\begin{array}{l}\% w \\
\text { yes }\end{array}$ & OR & $95 \% \mathrm{CI}$ & $\begin{array}{l}\% w \\
\text { no }\end{array}$ & $\begin{array}{l}\% w \\
\text { yes }\end{array}$ & OR & $95 \% \mathrm{CI}$ \\
\hline No PA/no AG (ref.) & 2,840 & 93.6 & 2,635 & 94.3 & 97.7 & 2.3 & 1.0 & - & 94.5 & 5.5 & 1.0 & - \\
\hline $\mathrm{PA} /$ no $\mathrm{AG}$ & 69 & 2.4 & 61 & 2.2 & 96.7 & 3.3 & 1.4 & $0.3-7.2$ & 71.2 & 28.8 & 6.8 & $3.5-13.2$ \\
\hline AG without PA & 58 & 2.0 & 53 & 1.9 & 81.8 & 18.3 & 8.3 & $3.5-19.3$ & 88.4 & 11.7 & 1.9 & $0.8-4.3$ \\
\hline AG with PA & 11 & 0.3 & 9 & 0.3 & 67.5 & 32.5 & 20.6 & $4.8-9.4$ & 40.7 & 59.4 & 21.3 & $5.5-83.3$ \\
\hline PD without $A G$ & 22 & 0.8 & 20 & 0.7 & 90.0 & 10.0 & 4.1 & $0.9-19.5$ & 58.2 & 41.8 & 10.7 & $4.0-28.7$ \\
\hline PD with AG & 20 & 0.8 & 18 & 0.6 & 44.9 & 55.1 & 45.1 & $16.4-124.0$ & 27.6 & 72.5 & 38.7 & $13.7-109.1$ \\
\hline
\end{tabular}

Follow-up status: follow-up groups are not mutually exclusive. No DSM-IV diagnosis: no PA, PD, AG, other anxiety disorder, mood disorders, somatoform disorders, eating disorders, alcohol dependence and illicit substance dependence. $\mathrm{n}=$ Unweighted number; $\mathrm{Ne}=$ eligible number (at least one follow-up assessment available); $\% \mathrm{w}=$ weighted percentage; $\mathrm{OR}=$ odds ratio from logistic regression; adjusted for sex and age at last assessment; n.d. = OR not defined due to empty cells. 
cases without any signs of PA or panic-like symptoms. Almost all comparisons were significantly different from the reference group of subjects without PA, AG or PD (data available on request). Further, AG with PA vs. AG without PA showed more work impairment, while AG with $P A$ vs. PD without $A G$ and $P D$ with $A G$ vs. PD without AG showed more leisure impairment. Regarding helpseeking, expected patterns emerged: participants with PD without AG were more likely to consult a medical doctor due to panic and less likely to do so for AG as compared to participants with AG (with or without PA). Help-seeking for both panic and AG was most pronounced in participants with co-occurring syndromes (PD with AG). Overall, participants with AG without PA were less likely to contact any health professional as compared to all other diagnostic groups. PD with AG was associated with the highest overall help-seeking rate, which was significantly greater than for individuals with PD without AG.

\section{Discussion}

The purpose of this study was to describe the relationship of AG with PA and PD by prospectively examining the natural course and development of each condition in the first three decades of life. Overall our findings indicated that AG is a clinically significant disorder that exists independently of PA and PD in a substantial number of cases. We came to this conclusion based on (a) different patterns of incidence and gender differentiation between PA, AG and PD, (b) differences in the temporal progres- sion and syndrome stability of AG with and without PA as well as PD with and without AG, (c) a lack of consistency regarding the role of temporally primary $\mathrm{PA}$ as the core pathogenic mechanism of onset for $A G$, as assumed in the DSM-IV, (d) patterns in salient clinical correlates and outcomes, and (e) the demonstration that even in AG cases without any indications of panic-like features similar impairment and outcomes were observed as those with PA. These findings do not call into question either the detrimental effects of PA or that there is a close, potentially casual link between initial PA and the onset of PD and AG in some cases. However, this association only accounts for about $50 \%$ of all agoraphobic subjects in this sample. These findings argue that AG should exist as a separate diagnostic category independent of PA and PD and suggest the elimination of the diagnostic hierarchy rules of DSM. Furthermore, the results provide evidence for the existence of various pathogenic pathways leading to AG.

With respect to incidence, the cumulative incidence of the DSM-IV categories PD with AG (1.5\%), PD without AG (1.9\%) and AG without history of PD (0.6\%) up to the age of 34 all lie within the range of reports in other general population studies [13, 14, 17-19, 22, 34, 45-57]. However, disregarding the DSM-IV hierarchy rules, we longitudinally confirmed previous findings that the incidences of DSM-IV PA (9.4\%) and AG (5.3\%) occur much more frequently than the rates of the above diagnoses together. Thus, consistent with previous cross-sectional findings, the occurrence of PA does not result in the onset of PD or AG in a large proportion of cases $[58,59]$.

\begin{tabular}{|c|c|c|c|c|c|c|c|}
\hline \multicolumn{4}{|c|}{ other anxiety disorders } & \multicolumn{4}{|c|}{ no DSM-IV diagnosis } \\
\hline $\begin{array}{l}\% w \\
\text { no }\end{array}$ & $\begin{array}{l}\% w \\
\text { yes }\end{array}$ & OR & $95 \%$ CI & $\begin{array}{l}\% w \\
\text { no }\end{array}$ & $\begin{array}{l}\% w \\
\text { yes }\end{array}$ & OR & $95 \% \mathrm{CI}$ \\
\hline 80.6 & 19.4 & 1.0 & - & 48.9 & 51.1 & 1.0 & - \\
\hline 62.6 & 37.4 & 2.4 & $1.4-4.3$ & 79.8 & 20.2 & 0.2 & $0.1-0.5$ \\
\hline 53.2 & 46.8 & 2.9 & $1.5-5.5$ & 79.7 & 20.3 & 0.3 & $0.1-0.6$ \\
\hline 0.0 & 100.0 & n.d. & & 100.0 & 0.0 & n.d. & \\
\hline 65.1 & 34.9 & 1.8 & $0.7-5.0$ & 76.9 & 23.1 & 0.3 & $0.1-1.1$ \\
\hline 31.5 & 68.5 & 7.4 & $2.5-21.6$ & 91.9 & 8.1 & 0.1 & $0.0-0.7$ \\
\hline
\end{tabular}


Considerations of the temporal progression and stability of syndromes point to diverse developmental pathways of PA, PD and AG. For instance, the observed mean and median age of onset was lower in AG than PA or PD. Further, although women's risk of developing one of these syndromes was elevated for each of the disorders, gender differences with respect to patterns of development were most profound for AG.

The results did not support the DSM-IV assumption that primary PA are predominantly associated with increased risks to develop AG. These findings were consistent in both the overall sample and in the more detailed strictly prospective examination. Instead, temporally primary PA or PD was found to be associated either moderately or not at all with subsequent AG. The findings are also inconsistent with claims that AG outside the panic spectrum is clinically irrelevant. The results revealed that only $20 \%$ remit and that these cases reveal a similar pattern of impairment and comorbidity. The relationship does not appear to be reciprocal, especially in cases of AG without PA. Thus, the noncomorbid manifestation of AG demonstrates different temporal patterns than PA and PD and appears to be qualitatively different.

Taken together, these results call into question the view that $A G$ is the mere consequence or complication of $\mathrm{PA}$ and $\mathrm{PD}$, as suggested in the prominent symptom progression model $[26,60]$, and may suggest (a) that this model applies only to a subgroup of patients $[4,11-19]$, (b) that neither the occurrence nor the anticipation of spontaneous panic is predictive of agoraphobic severity [61], (c) that AG and PD have at least some distinct genetic risk factors [62], and (d) that residual symptoms of $A G$ are a risk factor for relapse of panic in treated patients [63]. Alternative pathogenic mechanisms leading to AG are presently not as clear as those leading from AG to the relatively few cases with temporally secondary panic. Consistent with the speculation of Fava and Mangelli [63], we believe that the causal chain is dependent upon multiple pathways and multiple factors. One immediate and direct interpretation is that $A G$ is an independent phobic disorder in its own right, like social phobia or specific phobias. Although this study examined AG at the level of validated syndromes [4], previous studies suggest that an evaluation at the subclinical symptom level would actually increase the number of patients for whom PA/ $\mathrm{PD}$ is preceded by AG symptoms [63]. However, future studies are needed to further examine these issues in greater detail.

In terms of impairment, disability, help-seeking and comorbidity, all diagnostic groups revealed substantial complications even after accounting for the presence of comorbid conditions. Cases with comorbid PD and AG tended to have the least favorable clinical correlates. It is noteworthy that AG without PA was significantly less likely to seek help than all other diagnostic groups despite having a similar range of impairments. This supports the hypothesis of Weissman et al. [64] that a unidirectional relationship from PA to AG was valid for patients seeking help for panic symptoms, whereas patients with only AG remain at home and fail to seek treatment. If true, one might conclude that individuals with AG but without panic symptoms are not incapacitated enough to seek help $[4,65]$ and thus panic patients with $A G$ in former studies represented a help-seeking subtype.

This study had several strengths. First, developmental patterns of panic and AG were examined using a prospective 10-year longitudinal design with assessments close to the age of onset in a large community sample. Second, we analyzed the onset and incidence patterns of PA, PD and AG using a standardized diagnostic interview that allowed for nonhierarchical responses. This allowed us to investigate these conditions with and without the current DSM hierarchical rules and to extend previous studies by examining onsets conditional on one another. Third, the impact of recall bias and of potential diagnostic imprecision was further minimized by prospectively examining a subset of independently verified cases of AG established in a previous publication. These occurred in addition to overall analyses in the full data set. Finally, it should also be highlighted that our study provided a fuller incidence description than previous studies, most of which were cross-sectional and/or restricted to clinical samples.

The results of this study must be interpreted in light of several limitations. First, the age of onset analyses revealed that the high-risk period for the syndromes had not ended at the final follow-up of our fairly young respondents. Thus, a number of subjects in our sample might therefore still be at risk. As a result, our data can only apply to the first three decades of life and not beyond. Second, we observed selective attrition from baseline to follow-up for respondents with substance use disorders, including nicotine dependence. If cigarette smoking is a risk factor for PA $[66,67]$, the selective dropout may have led to an underestimation of PA and PD and consequently to an underestimation of cases with panic and AG. However, we did not find selective attrition for PA or AG. Third, the childhood age of onset retrospectively assessed at baseline is subject to memory bias. However, we are not aware of a memory bias that is spe- 
cific to only one of the syndromes and therefore it should not have an impact on the temporal relationship of panic and agoraphobic symptoms. Finally, this sample had a relatively low number of PD cases who, despite significant associations with impairment and help-seeking, may represent a less severe subgroup of PD relative to patients in clinical studies.

With these limitations in mind, we conclude that the differences in incidence patterns, the further progression and outcome, the syndrome stability over time and the existence of multiple reciprocal relationships between PA, AG and PD strongly suggest that AG exists as a clinically significant phobic condition independent of PD. The majority of agoraphobic subjects in this community sample have never experienced PA. This calls into question the current pathogenic assumptions underlying the present classification of $A G$ as being merely a consequence of panic. The findings are more consistent with the assumption of various pathogenic pathways and suggest a need for rethinking diagnostic concepts and changes in the DSM classification and diagnostic algorithms.

\section{Acknowledgments}

This work is part of the Early Developmental Stages of Psychopathology Study and is funded by the German Federal Ministry of Education and Research project No. 01EB9405/6, 01EB 9901/6, EB01016200, 01EB0140 and 01EB0440. Part of the field work and analyses were also additionally supported by grants of the Deutsche Forschungsgemeinschaft LA1148/1-1, WI2246/1-1, WI 709/7-1 and WI 709/8-1. Principal investigators are H.-U.W. and R.L. Core staff members of the Early Developmental Stages of Psychopathology Study group are: Dr. Kirsten von Sydow, Dr. Gabriele Lachner, Dr. Axel Perkonigg, Dr. Peter Schuster, M.H., Dipl.-Psych. Holger Sonntag, Dr. Tanja Brückl, Dipl.-Psych. Elzbieta Garczynski, Dr. Barbara Isensee, A.N., Dr. Chris Nelson, Dipl.-Inf. Hildegard Pfister, Dr. Victoria Reed, Dipl.-Soz. Barbara Spiegel, Dr. Andrea Schreier, Dr. Ursula Wunderlich, Dr. Petra Zimmermann, K.B. and Dr. Antje Bittner. Scientific advisors are Dr. Jules Angst (Zurich), Dr. Jürgen Margraf (Basel), Dr. Günther Esser (Potsdam), Dr. Kathleen Merikangas (NIMH, Bethesda, Md.), Dr. Ron Kessler (Harvard, Boston, Mass.) and Dr. Jim van Os (Maastricht). We also acknowledge the helpful comments of Katherine Shear to an earlier draft as well as the support of Jens Klotsche with regard to statistical analyses.

\section{References}

1 Spitzer RL, Williams JB: Proposed revisions in the DSM-III classification of anxiety disorders based on research and clinical experience; in Tuma AH, Maser JD (eds): Anxiety and the Anxiety Disorders. Hillsdale, Erlbaum Associates, 1985, pp 759-773.

2 Jablensky A: Approaches to the definition and classification of anxiety and related disorders in European psychiatry; in Tuma AH, Maser JD (eds): Anxiety and the Anxiety Disorders. Hillsdale, Erlbaum Associates, 1985, pp 735-758.

-3 Horwath E, Lish JD, Johnson J, Hornig CD, Weissman MM: Agoraphobia without panic: clinical reappraisal of an epidemiologic finding. Am J Psychiatry 1993;150:1496-1501.

4 Wittchen HU, Reed V, Kessler RC: The relationship of agoraphobia and panic in a community sample of adolescents and young adults. Arch Gen Psychiatry 1998;55:10171024

5 Craske MG: Is agoraphobic avoidance secondary to panic attacks?; in Widiger TA, Frances AJ, Pincus HA (eds): DSM-IV Sourcebook. Washington, American Psychiatric Association, 1996, pp 448-459.

-6 Bienvenu OJ, Onyike CU, Stein MB, Chen LS, Samuels J, Nestadt G, Eaton WW: Agoraphobia in adults: incidence and longitudinal relationship with panic. Br J Psychiatry 2006; 188:432-438
7 Hedley LM, Hoffart A: Agoraphobia without history of panic disorder. Clin Psychol Psychother 2001;8:436-443.

8 Maier W, Roth M, Buller R, Argyle N, Rosenberg R, Brandon S, Benkert O: Agoraphobia in panic disorder - An indicator of the severity of panic disorder or a distinct diagnostic entity. Psychiatr Ann 1991;21:374-381.

$\checkmark 9$ Katerndahl DA: Factors in the panic-agoraphobia transition. J Am Board Fam Pract 1989;2:10-16.

10 Lelliott P, Marks I, McNamee G, Tobena A: Onset of panic disorder with agoraphobia: toward an integrated model. Arch Gen Psychiatry 1989;46:1000-1004.

11 Angst J, Dobler-Mikola A: Anxiety states, panic and phobia in a young general population; in: World Psychiatry Congress Proceedings, Vienna. New York, Plenum Press, 1983.

12 Weissman MM, Leaf PJ, Holzer CE III, Merikangas KR: The epidemiology of anxiety disorders: a highlight of recent evidence. Psychopharmacol Bull 1985;21:538-541.

13 Wacker HR, Mullejans R, Klein KH, Battegay R: Identification of cases of anxiety disorders and affective disorders in the community according to ICD-10 and DSM-III-R by using the composite international diagnostic interview (CIDI). Int J Methods Psychiatr Res 1992;2:91-100.
14 Kessler RC, McGonagle KA, Zhao S, Nelson $\mathrm{CB}$, Hughes M, Eshleman S, Wittchen HU, Kendler KS: Lifetime and 12-month prevalence of DSM-III-R psychiatric disorders in the United States: results from the National Comorbidity Survey. Arch Gen Psychiatry 1994;51:8-19.

$\checkmark 15$ Hayward C, Killen JD, Taylor CB: The relationship between agoraphobia symptoms and panic disorder in a non-clinical sample of adolescents. Psychol Med 2003;33:733738.

16 Faravelli C, Abrardi L, Bartolozzi D, Cecchi C, Cosci F, D’Adamo D, Lo IB, Ravaldi C, Scarpato MA, Truglia E, Rossi Prodi PM, Rosi S: The Sesto Fiorentino study: point and one-year prevalences of psychiatric disorders in an Italian community sample using clinical interviewers. Psychother Psychosom 2004;73:226-234.

17 Weissman MM, Bland RC, Canino GJ, Faravelli C, Greenwald S, Hwu HG, Joyce PR, Karam EG, Lee CK, Lellouch J, Lepine JP, Newman SC, Oakley-Browne MA, RubioStipec M, Wells JE, Wickramaratne PJ, Wittchen HU, Yeh EK: The cross-national epidemiology of panic disorder. Arch Gen Psychiatry 1997;54:305-309. 
18 Kessler RC, Chiu WT, Jin R, Ruscio AM, Shear K, Walters EE: The epidemiology of panic attacks, panic disorder, and agoraphobia in the National Comorbidity Survey Replication. Arch Gen Psychiatry 2006;63:415424.

19 Eaton WW, Dryman A, Weissman MM: Panic and phobia; in Robins LN, Regier DA (eds): Psychiatric Disorders in America. The Epidemiological Catchment Area Study. New York, Free Press, 1991, pp 155-179.

-20 Magee WJ, Eaton WW, Wittchen HU, McGonagle KA, Kessler RC: Agoraphobia, simple phobia, and social phobia in the National Comorbidity Survey. Arch Gen Psychiatry 1996;53:159-168.

-21 Joyce PR, Bushnell JA, Oakley-Browne MA, Wells JE, Hornblow AR: The epidemiology of panic symptomatology and agoraphobic avoidance. Compr Psychiatry 1989;30:303312 .

22 Wittchen HU: Epidemiology of panic attacks and panic disorders; in Hand I, Wittchen HU (eds): Panic and Phobias - Empirical Evidence of Theoretical Models and Long-Term Effects of Behavioral Treatments. Berlin, Springer, 1986, pp 18-28.

23 Wittchen HU: Natural course and spontaneous remissions of untreated anxiety disorders: results of the Munich Follow-Up Study (MFS); in Hand I, Wittchen HU (eds): Panic and Phobias 2. Berlin, Springer, 1988, pp 317.

-24 Amering M, Katschnig H, Berger P, Windhaber J, Baischer W, Dantendorfer K: Embarrassment about the first panic attack predicts agoraphobia in panic disorder patients. Behav Res Ther 1997;35:517-521.

-25 Breier A, Charney DS, Heninger GR: Agoraphobia with panic attacks: development, diagnostic stability, and course of illness. Arch Gen Psychiatry 1986;43:1029-1036.

26 Klein DF: Anxiety reconceptualized; in Klein DF, Rabkin JG (eds): Anxiety. New Research and Changing Concepts. New York, Raven Press, 1981, pp 235-263.

$\checkmark 27$ Clum GA, Knowles SL: Why do some people with panic disorders become avoidant - A review. Clin Psychol Rev 1991;11:295-313.

-28 Craske MG, Barlow DH: A review of the relationship between panic and avoidance. Clin Psychol Rev 1988;8:667-685.

29 Goldstein AJ, Chambless DL: A reanalysis of agoraphobia. Behav Ther 1978;9:47-59.

30 Goisman RM, Warshaw MG, Steketee GS, Fierman EJ, Rogers MP, Goldenberg I, Weinshenker NJ, Vasile RG, Keller MB: DSM-IV and the disappearance of agoraphobia without a history of panic disorder: new data on a controversial diagnosis. Am J Psychiatry 1995;152:1438-1443.

31 Hand I, Wittchen HU: Panic and Phobias. Berlin, Springer, 1986.

32 Neudeck P, Wittchen HU: Konfrontationstherapie bei psychischen Störungen. Göttingen, Hogrefe, 2005
33 Koch EI, Gloster AT, Waller SA: Exposure treatments for panic disorder with and without agoraphobia; in Richard DCS, Lauterbach D (eds): Handbook of Exposure Therapies. San Diego, Academic Press, 2007, pp 221-246.

34 Reed V, Wittchen HU: DSM-IV panic attacks and panic disorder in a community sample of adolescents and young adults: how specific are panic attacks? J Psychiatr Res 1998;32:335-345.

35 Wittchen H-U, Perkonigg A, Lachner G, Nelson $\mathrm{CB}$ : Early developmental stages of psychopathology study (EDSP): objectives and design. Eur Addict Res 1998;4:18-27.

36 Lieb R, Isensee B, Sydow KV, Wittchen HU: The Early Developmental Stages of Psychopathology Study (EDSP): a methodological update. Eur Addict Res 2000;6:170-182.

37 Wittchen HU, Nelson CB, Lachner G: Prevalence of mental disorders and psychosocial impairments in adolescents and young adults. Psychol Med 1998;28:109-126.

38 Wittchen HU, Pfister H: DIA-X-Interviews: Manual für Screening-Verfahren und Interview; Interviewheft Längsschnittuntersuchung (DIA-X 12 Monate); Ergänzungsheft (DIA-X 12 Monate); PC-Programm zur Durchführung des Interviews (Längs- und Querschnittsuntersuchung); Auswertungsprogramm. Frankfurt, Swets \& Zeitlinger, 1997.

39 Wittchen H-U: Reliability and validity studies of the WHO - Composite International Diagnostic Interview (CIDI): a critical review. J Psychiatr Res 1994;28:57-84.

40 Reed V, Gander F, Pfister H, Steiger A, Sonntag H, Trenkwalder C, Sonntag A, Hundt W, Wittchen H-U: To what degree does the Composite International Diagnostic Interview (CIDI) correctly identify DSMIV disorders? Testing validity issues in a clinical sample. Int J Methods Psychiatr Res 1998;7:142-155.

41 Wittchen HU, Lachner G, Wunderlich U, Pfister H: Test-retest reliability of the computerized DSM-IV version of the Munich Composite International Diagnostic Interview (M-CIDI). Soc Psychiatry Psychiatr Epidemiol 1998;33:568-578.

42 American Psychiatric Association: Diagnostic and Statistical Manual of Mental Disorders, ed 4. Washington, American Psychiatric Association, 1994.

43 Royall RM: Model robust confidence intervals using maximum likelihood estimators. Int Stat Rev 1986;54:221-226.

44 Therneau TM, Grambsch PM: Modeling Survival Data. Extending the Cox Model. New York, Springer, 2000.

45 Jacobi F, Wittchen HU, Holting C, Hofler M, Pfister H, Muller N, Lieb R: Prevalence, comorbidity and correlates of mental disorders in the general population: results from the German Health Interview and Examination Survey (GHS). Psychol Med 2004;34:597611.
46 Bijl RV, Ravelli A, van Zessen G: Prevalence of psychiatric disorder in the general population: results of The Netherlands Mental Health Survey and Incidence Study (NEMESIS). Soc Psychiatry Psychiatr Epidemiol 1998;33:587-595.

47 Alonso J, Angermeyer MC, Bernert S, Bruffaerts R, Brugha IS, Bryson H, De Girolamo G, de Graaf R, Demyttenaere K, Gasquet I, Haro JM, Katz SJ, Kessler RC, Kovess V, Lepine JR, Ormel J, Polidori G, Russo LJ, Vilagut G, Almansa J, Arbabzadeh-Bouchez $\mathrm{S}$, Autonell J, Bernal M, Buist-Bouwman MA, Codony M, Domingo-Salvany A, Ferrer M, Joo SS, Martinez-Alonso M, Matschinger H, Mazzi F, Morgan Z, Morosini R, Palacin C, Romera B, Taub N, Vollebergh WAM: Prevalence of mental disorders in Europe: results from the European Study of the Epidemiology of Mental Disorders (ESEMeD) project. Acta Psychiatr Scand 2004;109:2127.

48 Eaton WW, Kessler RC, Wittchen HU, Magee WJ: Panic and panic disorder in the United States. Am J Psychiatry 1994;151:413420.

49 Faravelli C, Deglinnocenti BG, Giardinelli L: Epidemiology of anxiety disorders in Florence. Acta Psychiatr Scand 1989;79:308312.

50 Katerndahl DA, Realini JP: Lifetime prevalence of panic states. Am J Psychiatry 1993; 150:246-249.

\$1 Telch MJ, Lucas JA, Nelson P: Nonclinical panic in college students: an investigation of prevalence and symptomatology. J Abnorm Psychol 1989;98:300-306.

52 Weissman MM, Klerman GL, Markowitz JS, Ouellette R: Suicidal ideation and suicide attempts in panic disorder and attacks. N Engl J Med 1989;321:1209-1214.

$\checkmark 53$ Kessler RC, Berglund P, Demler O, Jin R, Walters EE: Lifetime prevalence and age-ofonset distributions of DSM-IV disorders in the National Comorbidity Survey Replication. Arch Gen Psychiatry 2005;62:593602

54 Lee CK, Kwak YS, Yamamoto J, Rhee H, Kim YS, Han JH, Choi JO, Lee YH: Psychiatric epidemiology in Korea. II. Urban and rural differences. J Nerv Ment Dis 1990;178:247252.

55 Hwu HG, Yeh EK, Chang LY: Prevalence of psychiatric disorders in Taiwan defined by the Chinese Diagnostic Interview Schedule. Acta Psychiatr Scand 1989;79:136-147.

56 Canino GJ, Bird HR, Shrout PE, Rubio-Stipec M, Bravo M, Martinez R, Sesman M, Guevara LM: The prevalence of specific psychiatric disorders in Puerto Rico. Arch Gen Psychiatry 1987;44:727-735. 
57 Grant BF, Hasin DS, Stinson FS, Dawson DA, Goldstein RB, Smith S, Huang B, Saha TD: The epidemiology of DSM-IV panic disorder and agoraphobia in the United States: results from the National Epidemiologic Survey on Alcohol and Related Conditions. J Clin Psychiatry 2006;67:363-374.

58 Goodwin RD, Brook JS, Cohen P: Panic attacks and the risk of personality disorder. Psychol Med 2005;35:227-235.

-59 Goodwin RD, Lieb R, Hoefler M, Pfister H, Bittner A, Beesdo K, Wittchen HU: Panic attack as a risk factor for severe psychopathology. Am J Psychiatry 2004;161:2207-2214.

60 Klein DF, Ross DC, Cohen P: Panic and avoidance in agoraphobia: application of path analysis to treatment studies. Arch Gen Psychiatry 1987;44:377-385.
61 Cox BJ, Endler NS, Swinson RP: An examination of levels of agoraphobic severity in panic disorder. Behav Res Ther 1995;33:5762.

-62 Gruppo Italiano Disturbi d'Ansia: Familial analysis of panic disorder and agoraphobia. J Affect Disord 1989;17:1-8.

63 Fava GA, Mangelli L: Subclinical symptoms of panic disorder: new insights into pathophysiology and treatment. Psychother Psychosom 1999;68:281-289.
64 Weissman MM, Leaf PJ, Blazer DG, Boyd JH, Florio BA: Panic disorder: clinical characteristics, epidemiology, and treatment. Psychopharmacol Bull 1986;22:787-791.

65 Andrews G, Slade T: Agoraphobia without a history of panic disorder may be part of the panic disorder syndrome. J Nerv Ment Dis 2002;190:624-630.

66 Zvolensky MJ, Feldner MT, Leen-Feldner EW, McLeish AC: Smoking and panic attacks, panic disorder, and agoraphobia: a review of the empirical literature. Clin Psychol Rev 2005;25:761-789.

-67 Isensee B, Wittchen HU, Stein MB, Hofler M, Lieb R: Smoking increases the risk of panic: findings from a prospective community study. Arch Gen Psychiatry 2003;60:692700 